\title{
Recent trends in gonorrhoea and syphilis epidemiology in Sweden: 2007 to 2011
}

I Velicko (inga.velicko@smi.se) ${ }^{1}$, M Unemo²

1. Swedish Institute for Communicable Disease Control (Smittskyddsinstitutet), Department of Epidemiology, Solna, Sweden

2. WHO Collaborating Centre for Gonorrhoea and other STIs, National Reference Laboratory for Pathogenic Neisseria,

Department of Laboratory Medicine, Clinical Microbiology, Örebro University Hospital, Örebro, Sweden

Citation style for this article:

Velicko I, Unemo M. Recent trends in gonorrhoea and syphilis epidemiology in Sweden: 2007 to 2011. Euro Surveill. 2012;17(29):pii=20223. Available online: http:// www.eurosurveillance.org/ViewArticle.aspx?Articleld=20223

Article submitted on 10 July 2012 / published on 19 July 2012

Gonorrhoea incidence in Sweden continued to increase during 2007-2011, while for syphilis, there was a very minor decrease, but no clear trend. Gonorrhoea incidence increased most among heterosexually infected men and women while for syphilis, the major burden was among men who have sex with men. Neisseria gonorrhoeae resistance to first-line antimicrobials increased annually. Surveillance of infection and antimicrobial resistance along with continuous analysis are needed, to develop prevention activities to reduce risk behaviours.

Recent reports from several European Union (EU) countries have revealed increases in gonorrhoea incidence, particularly in populations with higher frequency of spread of sexually transmitted infections (STIs), such as men who have sex with men (MSM) and young heterosexual individuals of both sexes (under 25 years of age), and stable or increasing syphilis incidence in MSM [1-4].

During the past couple of decades, Sweden has observed an increased incidence of gonorrhoea (since 1996) and syphilis (since 1999) [5-7]. MSM have been shown to be at increased risk of acquiring and spreading both gonorrhoea and syphilis $[5,6]$. Heterosexually infected men, especially those aged 25-34 years, also have a high gonorrhoea incidence compared with women [6]. During the last 10 years, women have constituted only approximately $20-30 \%$ of all gonorrhoea and syphilis cases in the country $[5,6]$. Disquietingly, during the past five years, gonorrhoea and syphilis incidences in heterosexually infected men and women, including those in younger age groups (under 25 years of age), have increased. Furthermore, as observed worldwide, antimicrobial resistance of Neisseria gonorrhoeae in Sweden has increased annually during this time, including to the recommended first-line cefixime and ceftriaxone $[6,8,9]$. One instance of treatment failure of pharyngeal gonorrhoea with ceftriaxone has been verified in Sweden [10].
In this report, we describe the trends from 2007 to 2011 for gonorrhoea, including antimicrobial resistance, and syphilis in Sweden, in order to identify recent changes in the epidemiology of the diseases and groups at risk.

\section{Surveillance of gonorrhoea and syphilis in Sweden}

The aetiologically based surveillance systems of the mandatorily reported gonorrhoea and syphilis in Sweden have been described elsewhere $[5,6]$. The gonorrhoea and syphilis case definitions used in Sweden are identical to those of the EU [11].

\section{TABLE}

Trends in gonorrhoea and syphilis in Sweden, 2007 and 2011

\begin{tabular}{|l|r|r|r|r|}
\hline & \multicolumn{2}{|c|}{ Gonorrhoea } & \multicolumn{2}{|c|}{ Syphilis } \\
\hline Item & 2007 & 2011 & 2007 & 2011 \\
\hline Total number of cases & 642 & 951 & 239 & 206 \\
\hline $\begin{array}{l}\text { Total incidence (number of cases } \\
\text { per 100,000 population) }\end{array}$ & 7.1 & 10.0 & 2.6 & 2.2 \\
\hline $\begin{array}{l}\text { Percentage of male cases } \\
\text { among all cases }\end{array}$ & $80 \%$ & $69 \%$ & $82 \%$ & $82 \%$ \\
\hline $\begin{array}{l}\text { Percentage of MSM among } \\
\text { all male cases }\end{array}$ & $38 \%$ & $40 \%$ & $57 \%$ & $66 \%$ \\
\hline $\begin{array}{l}\text { Percentage of adolescents and } \\
\text { young adults of both sexes } \\
\text { (aged 15-24 years) among all cases }\end{array}$ & $34 \%$ & $41 \%$ & $8 \%$ & $11 \%$ \\
\hline $\begin{array}{l}\text { Male-to-female case ratio } \\
\text { Percentage increase/decrease } \\
\text { observed in heterosexual male cases } \\
\text { in 2011 compared with } 2007\end{array}$ & $+3.2: 1$ & $2.2: 1$ & $4.8: 1$ & $5.1: 1$ \\
\hline $\begin{array}{l}\text { Percentage increase/decrease } \\
\text { observed in MSM cases in 2011 } \\
\text { compared with 2007 }\end{array}$ & $+35 \%$ & $-52 \%$ \\
\hline $\begin{array}{l}\text { Percentage increase/decrease } \\
\text { observed in female cases in 2011 } \\
\text { compared with } 2007\end{array}$ & $+147 \%$ & $-15 \%$ \\
\hline
\end{tabular}




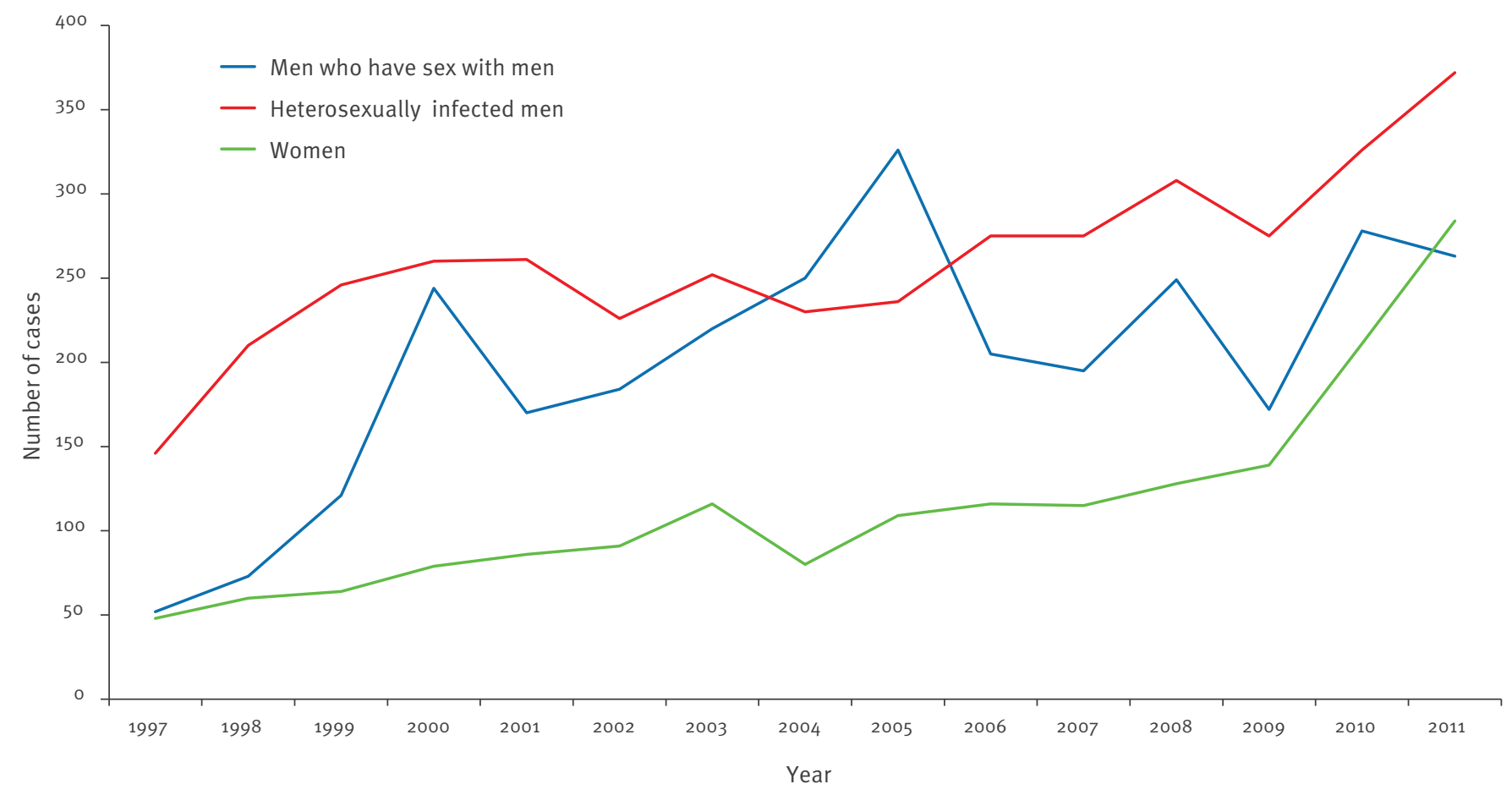

a Cases with unknown or other transmission route were excluded (a total of 8,924 cases were reported during this time).

For this study, all reported cases were extracted from the national surveillance database SmiNet [12], which is maintained by the Swedish Institute for Communicable Disease Control (Smittskyddsinstitutet. SMI). Surveillance data since 1997 are also presented as historical background of the gonorrhoea and syphilis incidences in Sweden. Population data for Sweden for the respective years were taken from Statistics Sweden [13].

\section{Gonorrhoea in Sweden}

From 2007 to 2011, the number of gonorrhoea cases increased by $48 \%$ (from 642 to 951 cases), reaching an incidence of 10.0 per 100,000 population in 2011 (Table). This increase was partly due to an increase (of $147 \%$ ) in the number of cases among women (Figure 1). We also observed an increase of $35 \%$ in the number of cases among heterosexually infected men (Figure 1). The proportion of cases who were heterosexually infected men increased from $52 \%$ in 2007 to $57 \%$ in 2011, while the proportion of MSM among cases remained relatively stable (38-40\%).

The increase among women was mostly observed in the age group 15-24 years, where the incidence increased by $154 \%$ (from 12.4 to 31.5 per 100,000 population) (Figure 2). During 2007 to 2011, a mean of $62 \%$ of all female cases was reported in this age group.
Among male cases, the largest increases were reported in the age groups $15-24$ and 25-34 years (Figure 2), which constituted a mean of $30 \%$ and $34 \%$, respectively, of all male cases during 2007 to 2011. During this time, the incidence increased by $31 \%$ (from 23.3 to 30.6 per 100,000 population) in men in the age group $15-24$ years and by $23 \%$ (from 30.9 to 38.0 per 100,000 population) in men aged 25-34 years (Figure 2).

During 2007 to 2011, about $70 \%$ of all the cases became infected in Sweden: a mean of $74 \%$ of the $15-24$ yearolds and $70 \%$ of the $25-34$ year-olds. In the remaining age groups, more than a mean of $50 \%$ were infected abroad. Of all cases infected abroad, the countries where the infection was most commonly acquired were Thailand, Philippines, Spain, Denmark and Germany. Women and MSM were more frequently infected in Sweden (a mean of $79 \%$ and $80 \%$ of the respective cases) than heterosexually infected men (a mean of $50 \%$ of cases).

\section{Neisseria gonorrhoeae resistance \\ to antimicrobials}

Resistance to the previous first-line antimicrobials for gonorrhoea treatment, ampicillin $(24-44 \%$ of isolates were resistant) and ciprofloxacin (55-75\%) remained high during 2007 to 2011. Azithromycin resistance ranged from $6 \%$ to $13 \%$ ( $11 \%$ in 2011). Decreased susceptibility or resistance to cefixime and ceftriaxone increased from less than $1 \%$ to $8 \%$ and $0 \%$ 


\section{FIGURE 2}

Gonorrhoea incidence by sex and age group (from 15 to 44 years), Sweden, 2000-2011 $(\mathrm{n}=6,933)^{\mathrm{a}}$
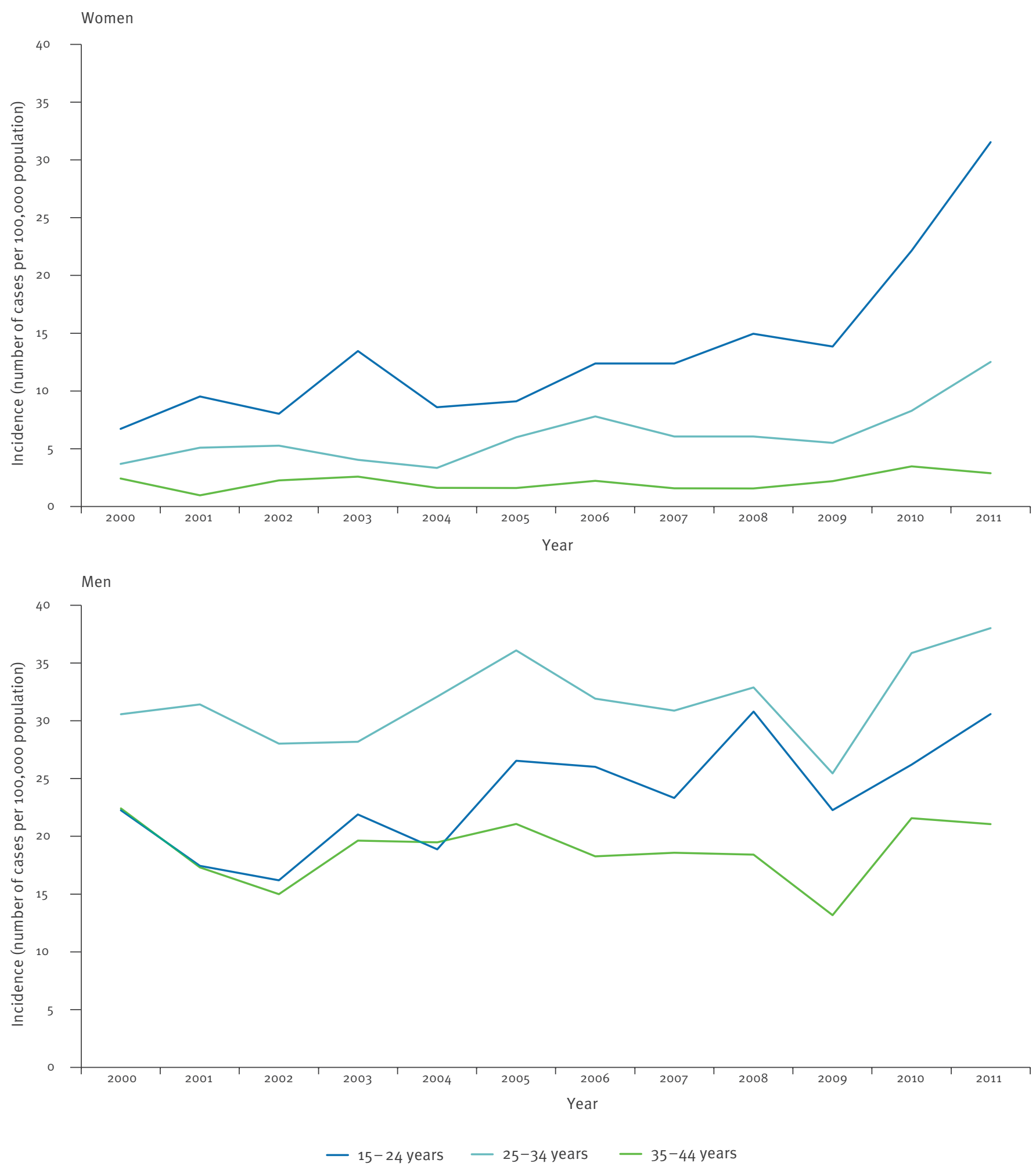

a Of the 7,908 cases reported during this time, 6,933 were aged 15-44 years. 
to $2 \%$, respectively. All isolates were susceptible to spectinomycin.

\section{Syphilis in Sweden}

From 2007 to 2011, the total incidence of syphilis showed a very minor decrease. However, due to the low number of cases and the large fluctuations in the number of cases annually (Figure 3), no clear trend in syphilis incidence could be observed. Thus the syphilis incidence, which started to increase in late-1990s, may now be stabilising. From 2007 to 2011, 172-277 cases were reported annually (incidence: $1.9-2.6$ per 100,000 population) (Figure 3, Table). Most cases (a mean of $79 \%$ ) were reported among men. A slight decrease (of $15 \%$ ) in incidence among women has been observed since 2007. However, for women in age group 25-34 years, incidence increased particularly between 2009 and 2011 (by 94\%). Among all female syphilis cases during 2007 to 2011, a mean of $41 \%$ were reported in this age group (25-34-years). In all other age groups, the incidence in women decreased during 2007-2011.

Among the male cases, the largest increase in incidence during the study period occurred between 2009 and 2011 and was mostly due to the increased incidences in the age groups $35-44$ (4.5 to 9.3 per 100,000 population) and 55-64 years ( 2.5 to 3.8 per 100,000 population). From 2007 to 2011, of all male cases, those aged
25-34 years constituted a mean of $27 \%$ and those aged $35-44$ years a mean of $31 \%$.

During 2007 to 2011, between $40 \%$ and $52 \%$ of all syphilis cases became infected in Sweden: a mean of $51 \%$ of the $15^{-24}$ year-olds and a mean of $51 \%$ of the 45-54 year-olds. In the remaining age groups, a mean of more than $50 \%$ were infected abroad. Of all cases infected abroad, the countries where the infection was most commonly acquired were Somalia, Iraq, Thailand, Germany and Denmark. Women and MSM were more frequently infected in Sweden (a mean of $45 \%$ and $67 \%$ of the respective cases) than heterosexually infected men (a mean of $34 \%$ of cases).

\section{Discussion}

The incidences of gonorrhoea and syphilis have been increasing since the mid/late-1990s in Sweden, as has also been observed in several other EU countries with well-functioning testing and surveillance systems [1-4]. However, the general trend in the EU, which contains many diverse countries, is a decline for both infections since the mid-2000s [14,15]. In Sweden, from 2007 to 2011 gonorrhoea incidence substantially increased among men (from both hetero- and homosexual transmission): in women, the increase was even more striking (Table). Observations of increased gonorrhoea (as well as syphilis) incidence in females and

\section{FIGURE 3}

Syphilis cases by route of transmission, Sweden, 1997-2011 $(\mathrm{n}=1,647)^{\mathrm{a}}$

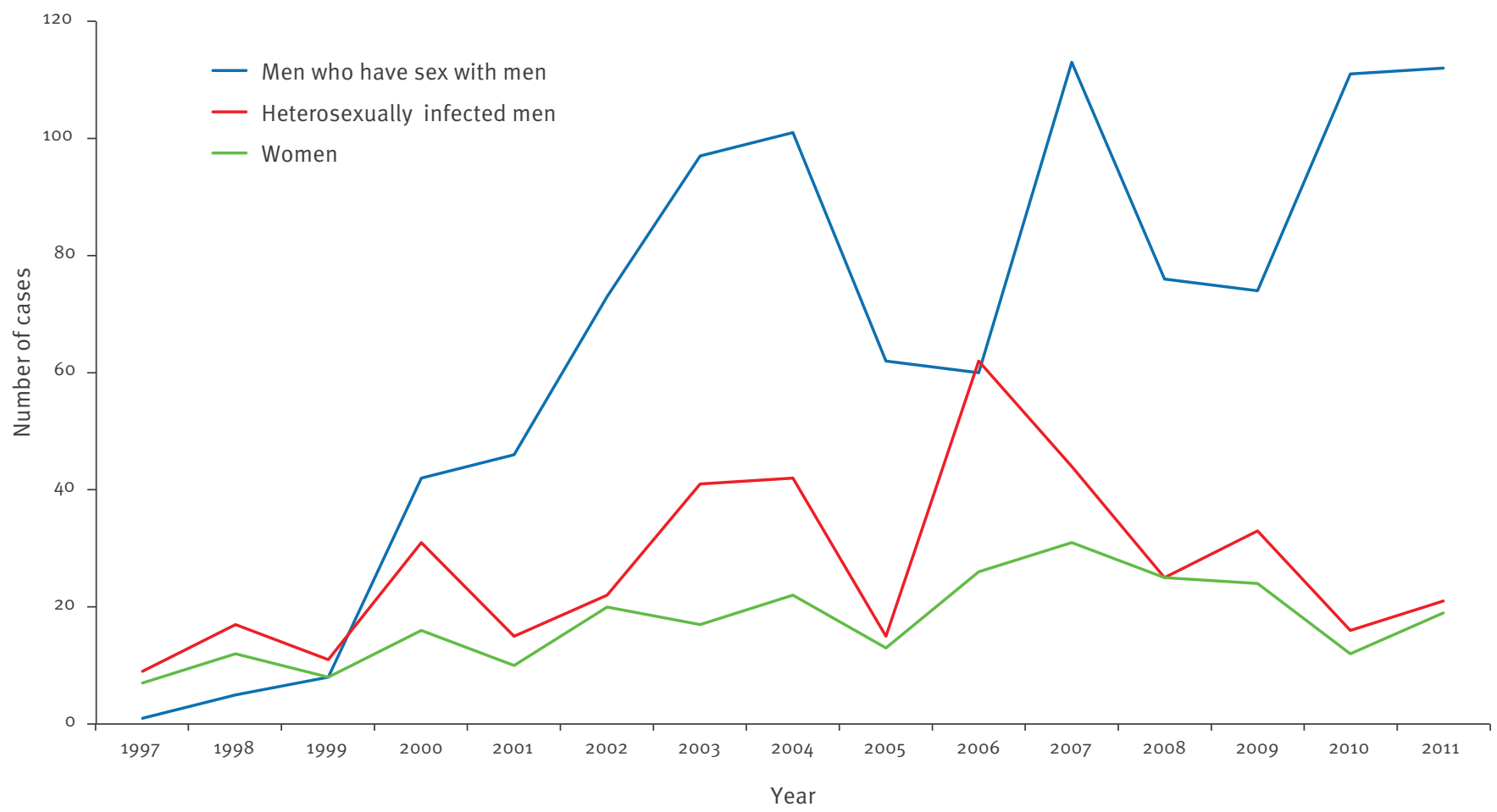

\footnotetext{
${ }^{a}$ Cases with unknown or other transmission route were excluded (a total of 2,078 cases were reported during this time).
} 
males (heterosexually infected and MSM) have also been recently reported in some EU countries [1-3]. In Sweden, since the late 1990s, a general increase in syphilis incidence has been observed among heteroand homosexual men, and women. However, from 2007 to 2011 , the total incidence of syphilis showed a very minor decrease, but due to the low number of cases and the large variation in the number of cases annually, no clear trend could be determined. Nevertheless, the syphilis incidence in Sweden, which started to increase in late-1990s, may now be stabilising.

Many different factors might contribute to the divergent gonorrhoea and syphilis trends from 2007 to 2011 in Sweden. Firstly, the increase in risky sexual behaviour in young predominantly heterosexual individuals, such as increased number of sexual partners over time, increased number of new casual sexual partners, and low level of condom use with casual sexual partners $[16,17]$, has presumably contributed to the increase in gonorrhoea in these highly sexually active young people. Gonorrhoea is also frequently imported from abroad by heterosexual men, which allows further spread of the infection domestically.

In these younger age groups of predominantly heterosexual individuals, syphilis remains relatively rare and does not have the same speed of spread, as it is mostly spreading among MSM in Sweden. In general, MSM are a group in which both gonorrhoea and syphilis are spread more easily due to more risky sexual behaviour such as unprotected anal intercourse, which makes them more prone to acquire STIs $[5,18]$. Some recent surveys among MSM in Sweden have demonstrated that an increased number of sexual partners during last year, unprotected anal intercourse during the last year, last sexual contact with a casual partner and sexual contact with an HIV-positive man are significantly associated with being diagnosed with chlamydia, gonorrhoea or syphilis during the last 12 months $[18,19]$. However, despite the large fluctuations in the exact number of cases annually among MSM in Sweden, the incidence of gonorrhoea and syphilis, which both started to increase in mid/late-1990s, may now be stabilising.

Other possible reasons for the observed trends is the increased awareness of healthcare workers in Sweden, which has contributed to increased uptake of testing, especially by young individuals being screened both for chlamydial infection and gonorrhoea [7] (an increasing number of youth health clinics in Sweden are offering screening for chlamydia infection and gonorrhoea from the same biological samples, using sensitive genetic tests for diagnosis). Syphilis testing is routinely only offered to new migrants, MSM, symptomatic patients, patients with unsafe sexual contacts with a syphilispositive patient, and HIV-positive patients. The epidemiology of syphilis in Sweden is also substantially affected by importation of the infection as a result of syphilis-positive individuals migrating from countries with a higher syphilis prevalence than in Sweden, as well as importation of infection by Swedish travellers: this accounts for the large variation in reported cases annually [7].

The importation of gonorrhoea by heterosexually infected Swedish men, predominantly after travel in Asia, might also introduce multidrug-resistant $N$. gonorrhoeae strains (defined in reference 8) in Sweden. Treatment failures with cefixime have been verified in Norway [20], England [21], Austria [22], France [23] and Sweden (unpublished data). It is of concern that the first gonococcal strains with highlevel resistance to ceftriaxone - the last remaining option for single antimicrobial empirical treatment of gonorrhoea - have been verified in Japan [24], France [23] and Spain [25]. In addition, ceftriaxone treatment failures of pharyngeal gonorrhoea have also been verified in Europe, in Sweden [10] and Slovenia [26]. In this emergent situation, the World Health Organization (WHO) has published a 'Global action plan to control the spread and impact of antimicrobial resistance in Neisseria gonorrhoeae' $[27,28]$ and the European Centre for Disease Prevention and Control (ECDC) has launched a response plan for the European Union [29].

Continuous monitoring and thorough analysis of trends in sexually transmitted infections in general and in syphilis and gonorrhoea in particular, including antimicrobial resistance, should be maintained in order to identify risk groups involved in transmission of these infections. Ideally, this analysis should include denominators such as number of individuals tested (including also negative individuals) and diagnostic method (including specific tests) used. More knowledge is crucial to better understand the changing epidemiology of sexually transmitted infections and plan prevention activities to better target particular populations at risk. 


\section{References}

1. Health Protection Agency (HPA). Sexually transmitted infections in men who have sex with men in the UK: 2011 report. London: HPA; 2011. Available from: http://www.hpa. org.uk/webc/HPAwebFile/HPAweb_C/1317131685989

2. Health Protection Agency (HPA). New data show sexually transmitted infection diagnoses on the rise in England. London: HPA; 31 May 2012. Press release. Available from: http://www.hpa.org.uk/webw/HPAweb\&HPAwebStandard/ HPAweb_C/1317134411572

3. Trienekens SC, Koedijk FD, van den Broek IV, Vriend HJ, Op de Coul EL, van Veen MG, et al. Sexually transmitted infections, including HIV, in the Netherlands in 2011. Bilthoven: National Institute for Public Health and the Environment (RIVM); 2012. RIVM report number 201051001/2012. Available from: http:// www.rivm.nl/dsresource?objectid=rivmp:181418\&type $=0$ rg\&di sposition=inline

4. Norwegian Institute of Public Health. Gonoré og syfilis i Norge 2011. [Gonorrhoea and syphilis in Norway, 2011]. Oslo: Norwegian Institute of Public Health. Norwegian. [Accessed 30 June 2012]. Available from: http://www.fhi.no/eway/default. aspx?pid=233\&trg=Area_5774\&MainArea_5661=5588:0:15,17 87:1:0:0:::0:0\&MainLeft 5588=5774:0:15,1787:1:0:0:::0:0\&Ar ea_5774=5544:97000::1:5776:1:::0:0

5. Velicko I, Arneborn M, Blaxhult A. Syphilis epidemiology in Sweden: re-emergence since 2000 primarily due to spread among men who have sex with men. Euro Surveill. 2008;13(50):pii=19063. Available from: http://www. eurosurveillance.org/ViewArticle. aspx?Articleld $=19063$

6. Velicko I, Unemo M. Increase in reported gonorrhoea cases in Sweden, 2001-2008. Euro Surveill. 2009;14(34): pii=19315. Available from: http://www.eurosurveillance.org/ViewArticle. aspx?Articleld $=19315$

7. Swedish Institute for Communicable Disease Control (SMI). Epidemiologisk årsrapport 2011. [Annual epidemiological report 2011]. Solna: SMI; 2012. Swedish. Available from: http://smi.se/upload/Publikationer/Epidemiologiskarsrapport-2012-15-6.pdf

8. Tapsall JW, Ndowa F, Lewis DA, Unemo M. Meeting the public health challenge of multidrug- and extensively drug resistant Neisseria gonorrhoeae. Expert Rev Anti Infect Ther. 2009;7(7):821-34

9. Stoltey JE, Barry PM. The use of cephalosporins for gonorrhea: an update on the rising problem of resistance. Expert Opin Pharmacother. 2012;13(10):1411-20.

10. Unemo M, Golparian D, Hestner A. Ceftriaxone treatment failure of pharyngeal gonorrhoea verified by international recommendations, Sweden, July 2010. Euro Surveill. 2011;16(6):pii=19792. Available from: http://www. eurosurveillance.org/ViewArticle.aspx?Articleld $=19792$

11. European Commission. Commission Decision of $28 / \mathrm{IV} / 2008$ amending Decision 2002/253/EC laying down case definitions for reporting communicable diseases to the Community network under Decision No 2119/98/EC of the European Parliament and of the Council. Official Journal of the European Union. Luxembourg: Publications Office of the European Union. 18.6.2008:L 159. Available from: http://eur-lex.europa.eu/ LexUriServ/LexUriServ.do?uri=0J:L:2008:159:0046:0090:EN: PDF

12. Swedish Institute for Communicable Disease Control (SMI). SmiNet - elektronisk anmälan av smittsamma sjukdomar. [SmiNet - electronic system for notification of mandatory reportable infections in Sweden]. Solna: SMI. Swedish. [Accessed 30 Jun 2012]. Available from: http://www.sminet.se

13. Statistics Sweden (SCB). Finding statistics/Statistical database/Population. Stockholm: SCB. [Accessed 30 Jun 2012]. Available from: http://www.ssd.scb.se/databaser/makro/ MainTable.asp?yp $=r q e x w r \& x u=A 4097001 \&$ mradekod $=B E \& 0$ mradetext $=$ Population \&lang $=2$ \&langd $b=2$

14. Savage EJ, Hughes G, Ison C, Lowndes CM, the European Surveillance of Sexually Transmitted Infections (ESSTI) network. Syphilis and gonorrhoea in men who have sex with men: a European overview. Euro Surveill. 2009;14(47):pii=19417. Available from: http://www. eurosurveillance.org/ViewArticle.aspx?Articleld=19417

15. European Centre for Disease Prevention and Control (ECDC). Sexually transmitted infections in Europe. 1990-2010. Stockholm: ECDC; 2012. Available from: http://www.ecdc. europa.eu/en/publications/Publications/201206-SexuallyTransmitted-Infections-Europe-2010.pdf

16. Tikkanen RH, Abelsson J, Forsberg M. UngKABog Kunskap, attityder och sexuella handlingar bland unga. [UngKABog - Knowledge, attitudes and sexual practices among young people]. Gothenburg: Gothenburg University; 2011. Swedish. Available from: https://gupea.ub.gu.se/ bitstream/2077/25017/2/gupea_2077_25017_2.pdf
17. Swedish Institute for Communicable Disease Control (SMI). Ungdomsbarometern 2011. Ungdomar och sexualitet 2011. Specialrapport för Smittskyddsinstitutet. [Youth Barometer 2011. Young people and sexuality 2011. Special report for the Swedish Institute for Communicable Disease Control]. Solna: SMI; 2011. Swedish. Available from: http://www. smittskyddsinstitutet.se/upload/Publikationer/hivsexprev/ Ungdomsbarometern/Ungdomsbarometern2011.pdf

18. Tikkanen RH. MSM-Enkäten. Riskhandlingar, hivtest och preventiva behov bland män som har sex med män. [MSM survey. Risk actions, HIV testing and prevention needs among men who have sex with men]. Malmö: Malmö högskola; 2010 Swedish. Available from: http://dspace.mah.se/bitstream/ handle/2043/10523/Fou_2010_4.pdf?sequence=1

19. Eriksson EL. Berglund T, Liljeros F, Tikkanen RH. Risk factors for self-reported STI analysed from a Swedish national MSM internet survey. Conference book of the Future of European Prevention among MSM (FEMP 2011), 10-11 November 2011, Stockholm, Sweden.

20. Unemo M, Golparian D, Syversen G, Vestrheim DF, Moi H. Two cases of verified clinical failures using internationally recommended first-line cefixime for gonorrhoea treatment, Norway, 2010. Euro Surveill. 2010;15(47):pii=19721. Available from: http://www.eurosurveillance.org/ViewArticle. aspx?Articleld $=19721$

21. Ison CA, Hussey J, Sankar KN, Evans J, Alexander S. Gonorrhoea treatment failures to cefixime and azithromycin in England, 2010. Euro Surveill. 2011;16(14): pii=19833. Available from: http://www.eurosurveillance.org/ViewArticle. aspx?Articleld $=19833$

22. Unemo M, Golparian D, Stary A, Eigentler A. First Neisseria gonorrhoeae strain with resistance to cefixime causing gonorrhoea treatment failure in Austria, 2011. Euro Surveill. 2011;16(43):pii=19998. Available from: http://www. eurosurveillance.org/ViewArticle.aspx?Articleld=19998

23. Unemo M, Golparian D, Nicholas R, Ohnishi M, Gallay A, Sednaoui P. High-level cefixime- and ceftriaxone-resistant N. gonorrhoeae in France: novel penA mosaic allele in a successful international clone causes treatment failure. Antimicrob Agents Chemother. 2012;56(3):1273-80.

24. Ohnishi M, Golparian D, Shimuta K, Saika T, Hoshina S, Iwasaku K, et al. Is Neisseria gonorrhoeae initiating a future era of untreatable gonorrhea?: detailed characterization of the first strain with high-level resistance to ceftriaxone. Antimicrob Agents Chemother. 2011;55(7):3538-45.

25. Cámara J, Serra J, Ayats J, Bastida T, Carnicer-Pont D, Andreu A, et al. Molecular characterization of two high-level ceftriaxoneresistant Neisseria gonorrhoeae isolates detected in Catalonia, Spain. J Antimicrob Chemother. 2012;67(8):1858-60.

26. Unemo M, Golparian D, Potočnik M, Jeverica S. Treatment failure of pharyngeal gonorrhoea with internationally recommended first-line ceftriaxone verified in Slovenia, September 2011. Euro Surveill. 2012;17(25):pii=20200. Available from: http://www.eurosurveillance.org/ViewArticle. aspx?Articleld $=20200$

27. World Health Organization (WHO). Global action plan to control the spread and impact of antimicrobial resistance in Neisseria gonorrhoeae. Geneva: WHO; 2012. Available from: http://www. who.int/reproductivehealth/publications/rtis/9789241503501

28. Ndowa F, Lusti-Narasimhan M, Unemo M. The serious threat of multidrug-resistant and untreatable gonorrhoea: the pressing need for global action to control the spread of antimicrobial resistance, and mitigate the impact on sexual and reproductive health. Sex Transm Infect. 2012;88(5):317-8.

29. European Centre for Disease Prevention and Control (ECDC). Response plan to control and manage the threat of multidrugresistant gonorrhoea in Europe. Stockholm: ECDC; 2012 Available from: http://www.ecdc.europa.eu/en/publications/ Publications/1206-ECDC-MDR-gonorrhoea-response-plan.pdf 